\title{
Efficacy of goniosynechialysis in the treatment of chronic angle-closure glaucoma: a five-case report
}

\author{
Eficácia da goniossinequiálise no tratamento do glaucoma \\ crônico de ângulo fechado: relato de cinco casos
}

Sebastião Cronemberger ${ }^{1}$, Artur Furst Loredo르. Daniela Silveira de Faria ${ }^{3}$, Nassim Calixto ${ }^{1}$

\begin{abstract}
We retrospectively analyzed the clinical data of five patients with chronic angle-closure glaucoma who underwent goniosynechialysis $(G S L)$. The patients presented a circumferential synechial angle-closure for less than or up to six months due to an acute primary angleclosure and a minimum six month follow up after GSL. After an average follow-up was of $32.4 \pm 13.9$ months, visual acuity improved in four $(80 \%)$ eyes. Before GSL, the intraocular pressure (IOP) varied from 34 to $58 \mathrm{mmHg}$. After GSL, the IOP varied from 8 to 44 mmHg. IOP was normalized by GSL with or without medication in $80 \%$ of the eyes. Before GSL, all patients were on maximum antiglaucomatous treatment including the use of $250 \mathrm{mg}$ of oral acetazolamide three times daily. After GSL, three patients no longer required antiglaucomatous medication and one needed to use one topical antiglaucomatous medication. GSL was effective and safe in four patients and unsuccessful in one patient. An increase of the GSL success rate occurs when it is associated with phacoemulsification and intraocular lens implantation.
\end{abstract}

Keywords: Glaucoma/surgery; Intraocular pressure; Ophthalmologic surgical procedures; Treatment outcome.

\section{RESUMO}

Analisamos retrospectivamente os dados clínicos de cinco pacientes com seio camerular fechado por sinéquias anteriores periféricas (SAP) secundárias à crise aguda de fechamento angular primário e submetidos à goniossinequiálise (GSL). Os pacientes apresentavam fechamento sinequial circunferencial por seis meses ou menos e foram acompanhados, no mínimo, por seis meses após a GSL. Após um acompanhamento médio de 32.4 13.9 meses, a acuidade visual melhorou em quatro ( $80 \%$ ) olhos. Antes da GSL, a pressão intraocular (Po) variou de 34 a $58 \mathrm{mmHg}$. Após a GSL, a Po variou de 8 a $44 \mathrm{mmHg}$. A Po foi normalizada pela GSL com ou sem medicação em $80 \%$ dos olhos. Antes da GSL, todos os pacientes estavam sob tratamento antiglaucomatoso máximo incluindo o uso de $250 \mathrm{mg}$ de acetazolamida por via oral três vezes ao dia. Após a GSL, três pacientes não mais necessitaram de medicação antiglaucomatosa e um paciente necessitou usar apenas uma medicação tópica antiglaucomatosa. A GSL foi eficaz e segura em quatro pacientes e não foi eficaz em um paciente. Ocorre um aumento da taxa de sucesso da GSL quando ela é associada à facoemulsificação com implante de lente intraocular.

Descritores: Glaucoma; Pressão intraocular; Procedimentos cirúrgicos oftalmológicos; Resultado de tratamento.

\footnotetext{
${ }^{1}$ Full Professor of Ophthalmology, Faculdade de Medicina da Universidade Federal de Minas Gerais (UFMG) - Belo Horizonte (MG), Brasil; ${ }^{2}$ Undergraduate Student, Faculdade de Medicina, Universidade Federal de Minas Gerais (UFMG) - Belo Horizonte (MG), Brasil; Bolsista de Iniciação Científica (PIBIC - CNPq);

${ }^{3} \mathrm{MD}$, Glaucoma Service, Hospital São Geraldo; Hospital das Clínicas, Universidade Federal de Minas Gerais (HC-UFMG) - Belo Horizonte (MG), Brasil.
}

Serviço de Glaucoma - Hospital São Geraldo, Hospital das Clínicas, Universidade Federal de Minas Gerais (HC-UFMG) - Belo Horizonte (MG), Brasil.

The authors declare no conflicts of interest

Recebido para publicação em: 20/5/2011 - Aceito para publicação em: 16/3/2012 


\section{INTRODUCTION}

$\mathbf{C}$ hronic angle-closure glaucoma (CACG) is characterized by the permanent angle-closure resulting from peripheral anterior synechiae (PAS) ${ }^{(1)}$. In many eyes that have undergone one or more episodes of acute primary angle-closure (APAC), the appearance of PAS is a consequence of the transformation of the appositional closure of the angle into a permanent closure. Peripheral anterior synechiae may also have other causes (uveitis, ocular trauma, post operative complications of glaucoma or cataract surgery or keratoplasty etc. $)^{(1)}$. Treatment of CACG remains challenging and in general, many eyes with this type of glaucoma become blind because the intraocular pressure (IOP) is extremely elevated and refractory to clinical treatment. The elevated IOP cannot be reduced to normal levels even under maximum topical antiglaucomatous treatment and/or conventional antiglaucomatous surgery (trabeculectomy with antimitotic).

Goniosynechialysis (GSL) is a surgical procedure that aims to cut the PAS from the trabecular meshwork that still has a hypothetically normal function ${ }^{(2-5)}$. In literature, some papers have shown that GSL combined or not with phacoemulsification can obtain good results in eyes with CACG, especially in those with less than six months of the PAS appearance ${ }^{(2-9)}$. Canlis et al. ${ }^{(10)}$ showed that ultrasound biomicroscopy (UBM) can be useful in evaluating pre and postoperative GSL. In Brazil, there is only one case report of GSL performed by one of the authors (SC) ${ }^{(11)}$. It was carried out on a patient with PAS due to two episodes of acute primary angle-closure that did not respond to conventional clinical treatment. This case was included in this series.

The aim of this study is to evaluate the effectiveness and safety of GSL in patients with CACG due to APAC.

\section{Methods}

We retrospectively analyzed the charts of five patients with CACG who underwent GSL at the Glaucoma Service of São Geraldo Hospital in the period from January, 2005 to february, 2011. This study was approved by the Research Ethics Committee of the Federal University of Minas Gerais.

We registered the demographics, cause of CACG, visual acuity (VA), IOP, conventional gonioscopy with a Goldmann three-mirror lens, indentation gonioscopy with a Zeiss four-mirror goniolens and medication before and after GSL. We included only patients who had had one or more APAC episodes with a circumferential synechial angle-closure (PAS in $360^{\circ}$ of the angle) for less than or up to six months and a minimum six month follow-up after GSL. Preoperatively, we performed ultrasound biomicroscopy (UBM) in all eyes. The GSL's technique (Figure 1) was the same in all patients and performed by the same doctor (SC). It consisted of two paracentesis, one nasal and the other temporal, both performed with a \# 15 scalpel. Afterwards, the anterior chamber was deepened more than its normal depth by the injection of $2 \%$ methylcellulose. The patient's head was inclined to one side in order that the surface of the iris was parallel to the optical axis of the microscope. We used the Swan-Jacob gonioprism lens (Ocular Instruments Inc., Bellevue, WA) (Figure 2) in order to better visualize the synechial region and its extension such as it was done by other authors ${ }^{(12,13)}$. We then introduced a delicate spatula pressing posteriorly its tip around $360^{\circ}$ of the angle against the most peripheral iris adjacent to the point of angle adhesion until the trabecular meshwork was exposed. This maneuver was repeated along the circumference of the peripheral iris until the angle was opened. The methylcellulose was removed and replaced with a balanced saline

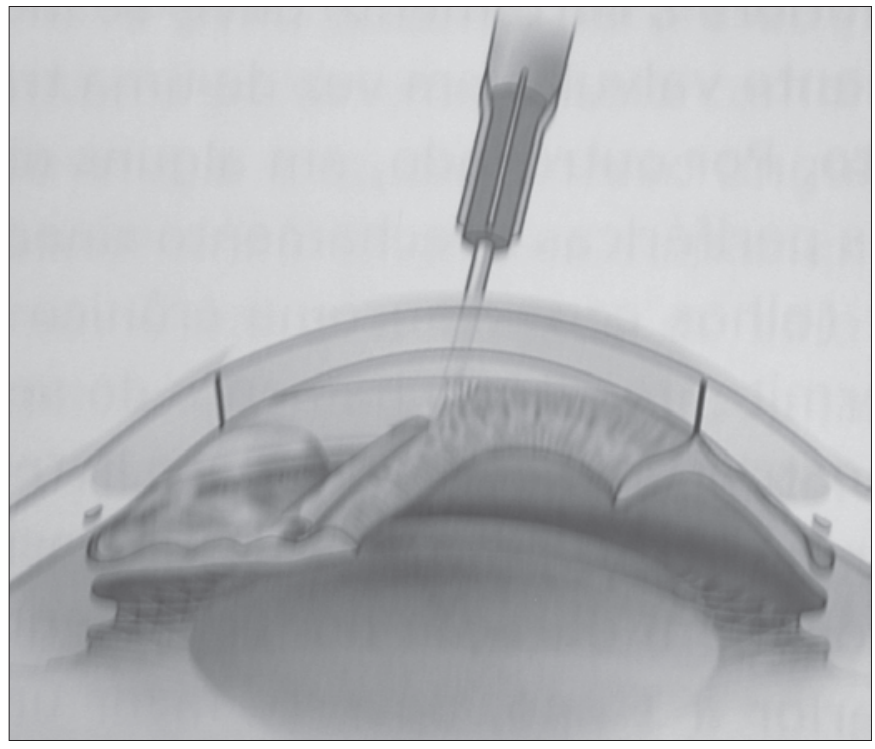

Figure 1: Scheme showing the goniosynechialysis' technique (from: Almeida $H G$, Boteon J. Glaucoma associado à ceratoplastia penetrante. In: Almeida HG, Cohen R, editores. Glaucomas secund $\$$ rios; 2 a ed. São Paulo: Roca; 2006. p. 311-25). Note the opened angle at the left and the angle-closure at the right

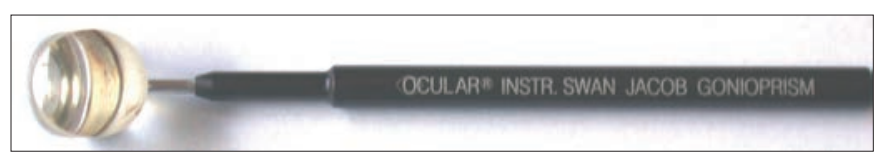

Figure 2: Suan-Jacob gonioprism lens

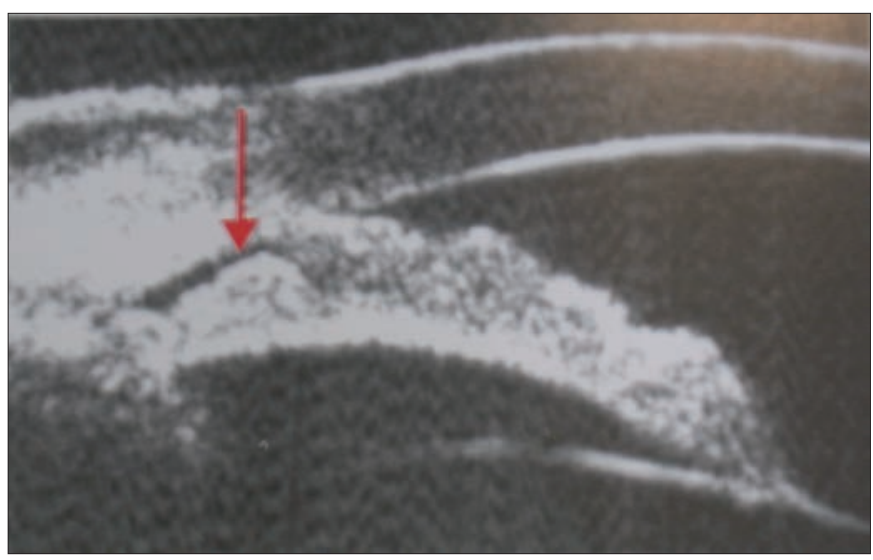

Figure 3: UBM image illustrating an open region (red arrow) of the angle behind the synechial angle-closure region

solution. In two eyes, GSL was the only procedure and in three others having cataracts GSL was performed following corneal clear phacoemulsification with intraocular lens implantation at the same occasion. After GSL, we prescribed $0.1 \%$ prednisolone six times a day and $1 \%$ atropine three times a day, tapered within six weeks, and antibiotic drops four times a day for seven days. In cases with inflammatory reaction (plasmoid anterior chamber reaction), $40 \mathrm{mg}$ of oral prednisolone were prescribed for five days. The IOP was measured on the first post operative day, at one, three and six months and at the last visit. In those eyes in which the post operative IOP was still elevated, the pre operative 
Table 1

Number of patients using antiglaucomatous eye drops and oral acetazolamide before and after GSL

\begin{tabular}{lcc}
\hline Use of medication & Pre GSL & Post GSL \\
\hline Patients using 250 mg of oral acetazolamide three times daily & 5 & 1 \\
Patients not using antiglaucomatous eye drops & 0 & 3 \\
P Patients using one antiglaucomatous eye drop & 0 & 1 \\
Patients using three antiglaucomatous eye drops & 5 & 1 \\
Average number of antiglaucomatous eye drops & $3.0 \pm 0.0$ & $0.8 \pm 1.3$ \\
\hline
\end{tabular}

GSL- goniosynechialysis

Table 2

Demographics, cause of chronic angle-closure glaucoma, visual acuity, pre and last post intraocular pressure, and follow-up of patients who underwent goniosynechialysis

\begin{tabular}{|c|c|c|c|c|c|c|c|c|c|c|}
\hline $\begin{array}{l}\text { Patient/ } \\
\text { Eye }\end{array}$ & $\begin{array}{c}\text { Age/ } \\
\text { Gender }\end{array}$ & Race & $\begin{array}{c}\text { Cause of } \\
\text { CACG }\end{array}$ & Surgery & $\begin{array}{c}\text { APAC } \\
\text { time(mos.) }\end{array}$ & $\begin{array}{c}\text { Pre } \\
\text { GSLVA }\end{array}$ & $\begin{array}{c}\text { Post } \\
\text { GSLVA }\end{array}$ & $\begin{array}{c}\text { Pre } \\
\text { GSLIOP }\end{array}$ & $\begin{array}{c}\text { Post } \\
\text { GSLIOP }\end{array}$ & $\begin{array}{c}\text { Follow-up } \\
\text { (mos.) }\end{array}$ \\
\hline $1 / \mathrm{LE}$ & $65 / F$ & Mullato & APAC & Phaco/GSL & 1 & LP & 1 & 40 & 14 & 42 \\
\hline $2 / \mathrm{LE}$ & $60 / \mathrm{F}$ & Mullato & APAC & GSL & 3 & LP & LP & 54 & 44 & 10 \\
\hline 3/RE & $63 / F$ & White & APAC & GSL & 2 & $\mathrm{HM}$ & 1 & 50 & 14 & 23 \\
\hline 4/RE & $52 / \mathrm{M}$ & Mullato & APAC & Phaco/GSL & 1 & 0.1 & 0.4 & 58 & 17 & 48 \\
\hline $5 / \mathrm{RE}$ & $66 / \mathrm{F}$ & White & APAC & Phaco/GSL & 3 & 0.05 & 0.7 & 34 & 8 & 39 \\
\hline
\end{tabular}

CACG - chronic angle-closure glaucoma; APAC - acute primary angle-closure; GSL - goniosynechialysis; VA - visual acuity; IOP - intraocular pressure; Phaco - phacoemulsification; F - female; M - male; mos. - months; LE - left eye; RE - right eye; LP - light perception; HM - hand movements

antiglaucomatous medication was used. The complications during and after GSL were registered. We compared the pre and post operative data.

\section{RESULTS}

We included five patients, four (80\%) females and one $(20 \%)$ male with ages ranging from 52 to 66 years old $(61.2 \pm 5.0)$. Three $(60 \%)$ patients were mullato and two $(40 \%)$ white.

The indentation gonioscopy exam revealed that synechial angle-closure was present before GSL in $360^{\circ}$ of the angle in all eyes. Three $(60 \%)$ patients developed PAS after one APAC episode and two $(40 \%)$ patients after two APAC episodes. Pre operative UBM confirmed the synechial angle-closure in all eyes. In two (40\%) eyes (patients 1 and 5) UBM revealed a small opening of the angle behind the synechial angle-closure region. The circumferential synechial angle-closure was due to APAC in all eyes $(100 \%)$. All patients were taking $250 \mathrm{mg}$ of oral acetazolamide three times daily plus three antiglaucomatous eye drops. The GSL was the only procedure in two (40\%) eyes (Patients 2 an 3). In the other three (60\%) eyes (patients 1, 4 and 5), GSL was performed at the same occasion, following phacoemulsification and intraocular lens implantation. Before GSL, the IOP had a minimum value of $34 \mathrm{mmHg}$ and a maximum value of $58 \mathrm{mmHg}$ with a median equal to $50 \mathrm{mmHg}$ and a standard deviation equal to 9.96. After GSL and at the average follow-up of $32.4 \pm 15.6$ months, the IOP had a minimum value of $8 \mathrm{mmHg}$ and a maximum value of $44 \mathrm{mmHg}$ with a median equal to $14 \mathrm{mmHg}$ and a standard deviation equal to 14.1. Considering only the four eyes in which GSL was successful, the average pre operative IOP dropped from $45.5 \pm 10.6$ to $13.3 \pm 3.8 \mathrm{mmHg}$ post GSL.

At the last examination, conventional gonioscopy (Goldmann three-mirror lens) showed that the angle was circumferentially opened in four $(80 \%)$ eyes. In one eye (patient 3 ), there was an angle re-closure. Three $(60 \%)$ eyes no longer required antiglaucomatous medication and one $(20 \%)$ needed to use one topical antiglaucomatous medication. In one eye (Patient 3), GSL was unsuccessful. This patient had had two APAC episodes before GSL. After GSL, despite the instillation of 1\% atropine eye drops (three times a day), topical corticosteroid (six times a day) and antibiotic eye drops (four times a day), the angle showed a PAS reclosure. This patient remained using three antiglaucomatous eye drops and using $250 \mathrm{mg}$ of oral acetazolamide three times daily and abandoned the treatment. The average number of antiglaucomatous eye drops per patient decreased from $3.0 \pm 0.0$ before GSL to $0.8 \pm 1.3$ after GSL. Table 1 shows the comparison of antiglaucomatous medication used by patients before and after GSL.

The best corrected pre operative VA varied from light perception (two eyes) to 0.1 (one eye). In the last examination, the best corrected VA improved in four $(80.0 \%)$ eyes. Two eyes had normal VA, one had VA equal to 0.7 and one, equal to 0.4 . The VA remained the same (LP) in one $(20 \%)$ eye. Hyphema was observed as a complication in per and postoperative in three $(60 \%)$ patients. In the post operative period, the hyphema disappeared within one week. Plasmoid anterior chamber reaction occurred after GSL in two (40\%) eyes (patients 2 and 3). These patients used $40 \mathrm{mg}$ of oral prednisolone for five days with the disappearance of the reaction. Table 2 summarizes the findings in patients undergoing GSL

\section{DiscusSION}

The diagnosis of CACG requires the complete ocular disease history and a careful workup which includes slit lamp examination, IOP measurement and indentation gonioscopy. The aim of treating CAGC is to eliminate the underlying pathophysiological 
mechanism and consequently normalizing the IOP.

Goniosynechialysis is a surgical procedure designed to remove PAS in an attempt to restore the physiological drainage of aqueous humor in eyes with glaucoma refractory to medical treatment and/or conventional surgery. According to literature, GSL can obtain good results in about $80 \%$ of eyes in which PAS has been present for up to one year after acute glaucoma or after other types of refractory glaucoma ${ }^{(2-9)}$. GSL is mainly indicated when PAS with at least $180^{\circ}$ has been present for less or up to a year. It can be associated with other procedures such as trabeculotomy or phacoemulsification with or without intraocular lens implantation ${ }^{(6-9,14,15)}$. In this paper, GSL was the only surgical procedure in two $(40 \%)$ eyes. In them, GSL was successful in one $(50 \%)$ eye but it was unsuccessful in the other eye $(50 \%)$ in which the IOP was previously much elevated. In three $(60 \%)$ eyes, GSL was associated with phacoemulsification and intraocular lens implantation as it was done by other authors ${ }^{(6,15)}$. In association with phacoemulsification and intraocular lens implantation, the GSL success rate was $100 \%$. Overall, the GSL success rate was $80 \%$. This is in agreement with previously published literature ${ }^{(2-9)}$. As phacoemulsification with intraocular lens implantation does not cause significant IOP reduction, it seems to be clear that the IOP control was due to GSL. In patients 1, 2 and 4, the phacoemulsification and intraocular lens implantation was responsible for an extraordinary VA improvement.

It is very important to emphasize that in spite of the fact that four eyes (patients 1, 2, 3 and 4) in this series had pre operatively presented a very high IOP (equal to or higher than $40 \mathrm{mmHg}$ ) refractory to the conventional clinical treatment, GSL was crucial in normalizing the IOP.

Before performing GSL, the indentation gonioscopic exam is indispensable because it provides the differentiation between an appositional angle-closure and a permanent synechial angleclosure. All UBM images taken from the five eyes confirmed the findings of the indentation gonioscopy. As it was demonstrated by some authors, UBM can be useful in evaluating pre and post operative $\mathrm{GSL}^{(10)}$. In our experience, UBM can reveal, before GSL, a small opening of the angle behind the synechial angleclosure region as is shown on Figure 3. This finding can be useful and important for the indication and the prognosis of GSL. Also, it is necessary to emphasize that a short duration of the synechial angle-closure might improve the prognosis for GSL as occurred in four eyes of this series. In patients 1,3 and 4, GSL or phacoemulsification with GSL was performed between one and two months after the APAC crisis. In the other patients, GSL alone (patient 2) or phacoemulsification with GSL (patient 5) was performed at three months after two APAC episodes. GSL was successful in patient 5, whose IOP before GSL was much lower $(34 \mathrm{mmHg})$ than that of patient $2(54 \mathrm{mmHg})$ in whom GSL was unsuccessful.

When the synechial angle-closure is prolonged (more than one year), it can lead to irreversible scarring of the trabecular meshwork $^{(2)}$. In such cases, GSL is ineffective.

GSL may have complications ${ }^{(4)}$. Plasmoid anterior chamber reaction may occur as well as iridodialysis, ciclodyalisis, and irregular pigmentation of the re-exposed trabecular meshwork, secondary cataract and re-closure of the PAS. In this series, plasmoid anterior chamber reaction occurred in two (40\%) eyes (Patients 2 and 3). After using $40 \mathrm{mg}$ of oral prednisolone for five days the plasmoid reaction disappeared. The hyphema may result from lysis of the synechia ${ }^{(2)}$. In this series, hyphema was observed during and after surgery in three $(60 \%)$ eyes. The hyphema disappeared in the first week after GSL. To minimize the chance of GSL complications, the surgical maneuvers must be done very delicately. An important aspect is the prevention of PAS re-closure. To avoid this, the instillation of $1 \%$ atropine eye drops (three times a day), topical corticosteroid (six times a day), and antibiotic eye drops (four times a day) tapered within six weeks is mandatory. In some cases $40 \mathrm{mg}$ of prednisone orally administered for five days might be necessary. In this series, GSL was unsuccessful in only one eye in which a PAS re-closure occurred despite the use of $1 \%$ atropine (three or four times a day), topical corticosteroid (six times a day), and antibiotic eye drops (four times a day) and $40 \mathrm{mg}$ of prednisone orally administered for five days.

\section{Conclusion}

Goniosynechialysis is an effective and safe procedure for the treatment of chronic angle-closure glaucoma. The GSL success rate is increased when it is performed in association with phacoemulsification and intraocular lens implantation.

\section{REFERENCES}

1. Amerasinghe N,Aung T. Angle-closure: risk factors, diagnosis and treatment. Prog Brain Res. 2008;173:31-45.

2. Campbell DG, Vela A. Modern goniosynechialysis for the treatment of synechial angle-closure glaucoma. Ophthalmology. 1984:91(9):1052-60.

3. Shingleton BJ, Chang MA, Bellows AR, Thomas JV. Surgical goniosynechialysis for angle-closure glaucoma. Ophthalmology. 1990;97(5):551-6.

4. Tanihara H, Nishiwaki K, Nagata M. Surgical results and complications of goniosynechialysis. Graefes Arch Clin Exp Ophthalmol. 1992:230(4):309-13.

5. Tanihara H,Negi A,Akimoto M,Nagata M. Long-term results of nonfiltering surgery for the treatment of primary angle-closure glaucoma. Graefes Arch Clin Exp Ophthalmol. 1995;233(9):563-7.

6. Teekhasaenee C, Ritch R. Combined phacoemulsification and goniosynechialysis for uncontrolled chronic angle-closure glaucoma after acute angle-closure glaucoma. Ophthalmology.1999;106(4):66974; discussion 674-5.

7. Lai JS, Tham CC, Chua JK, Lam DS. Efficacy and safety of inferior 180 degrees goniosynechialysis followed by diode laser peripheral iridoplasty in the treatment of chronic angle-closure glaucoma. J Glaucoma. 2000;9(5):388-91.

8. Assalian A, Sebag M, Desjardins DC, Labelle PF. Successful goniosynechialysis for angle-closure glaucoma after vitreoretinal surgery. Am J Ophthalmol. 2000;130(6):834-5.

9. Lai JS, Tham CC, Lam DS. The efficacy and safety of combined phacoemulsification, intraocular lens implantation, and limited goniosynechialysis, followed by diode laser peripheral iridoplasty, in the treatment of cataract and chronic angle-closure glaucoma. J Glaucoma. 2001;10(4):309-15.

10. Canlas OA, Ishikawa H, Liebman JM, Tello C, Ritch R. Ultrasound biomicroscopy before and after goniosynechialysis. Am J Ophthalmol. 2001;132(4):570-1.

11. Cronemberger S. Goniossinequiálise no tratamento do glaucoma crônico congestivo. Universo Visual. 2005;24:20-2.

12. Takanashi T, Masuda H, Tanito M, Nonoyama S, Katsube T, Ohira A Scleral indentation optimizes visualization of anterior chamber angle during goniosynechialysis. J Glaucoma. 2005;14(4):293-8.

13. Fang AW, Yang XJ, Nie L, Qu J. Endoscopically controlled goniosynechialysis in managing synechial angle-closure glaucoma. J Glaucoma. 2010;19(1):19-23.

14. Harasymowycz PJ, Papamatheakis DG, Ahmed I, Assalian A, Lesk M, Al-Zafiri Y, et al. Phacoemulsification and goniosynechialysis in the management of unresponsive primary angle closure. J Glaucoma. 2005;14(3):186-9.

15. Kiuchi Y, Tsujino C, Nakamura T, Otori Y, Mochizuki $H$ Phacoemulsification and trabeculotomy combined with goniosynechialysis for uncontrollable chronic angle-closure glaucoma. Ophthalmic Surg Lasers Imaging. 2010;41(3):348-54.

\section{Autor correspondente:}

Sebastião Cronemberger

Rua Martim de Carvalho, no 410/501 - Santo Agostinho

CEP 30190-090 - Belo Horizonte - MG

E-mail: secronem@gmail.com 